\title{
A mediação humana entre cristianismo e sociedade no Documento de Aparecida
}

\author{
Marcelo Batalioto
}

\section{Introdução}

No curso da história nos deparamos com a pós-modernidade, um tempo crítico que anula as grandes narrativas e onde qualquer síntese é meramente provisória. $\mathrm{O}$ ser humano se caracteriza a partir da sua subjetividade e para atingir esse ser humano a partir da religiosidade é preciso considerá-lo como pessoa e sujeito. Só a partir daí é que a mensagem cristã terá sentido. O ser humano é cada vez mais uma personalidade aberta autenticada pela liberdade. ${ }^{1}$

Ao dizer pós-modernidade estamos supondo naturalmente algo que a antecede, ou seja, a própria modernidade. Esse período histórico é caracterizado pela tensão entre sociedade e Igreja. Uma tensão que gerou rupturas, com prejuízos para ambos os lados, mas também aprendizados comuns. A Igreja aprendeu e continua aprendendo a relevância fundamental do humano para falar de Deus. Por outro lado, as abordagens antropológicas da racionalidade moderna que aprisionam o ser humano na pura imanência, cerceando seu espírito e sua abertura natural para a transcendência também são limitadas e até perigosas.

O tempo tem ensinado que a Igreja precisa dispor daquilo que é seu maior tesouro, ou seja, a essência cristã contida na Boa Nova de Jesus Cristo para atingir positiva e construtivamente o ser humano na época atual.

\footnotetext{
${ }^{1}$ K. RAHNER, Curso fundamental da fé, São Paulo, Paulus, 2004, p. 39.
} 
Um bom tanto dessa intuição foi captada pela Igreja representada em Aparecida. Dessa Conferência surge um documento (DA) que procura ler a realidade atual.

As conclusões da Conferência propõem apelos marcantes quando conclama todos os cristãos a se converterem a Jesus Cristo para cumprir sua missão de discípulos missionários nesse Continente que precisa repensar e ressignificar sua forma de ser cristão.

Porém, mais do que apelos, será preciso audácia para buscar um novo modelo eclesial, não somente um modelo teórico, mas que seja efetivo para tornar a Igreja mais leve e capaz de se mover com mais agilidade, a fim de promover uma evangelização marcadamente querigmática. Nessa nova forma de evangelização a Igreja, enquanto instituição, deverá gradativamente se retirar do centro da referência, para que cada vez mais transpareçam Jesus Cristo e o ser humano como destinatário da Boa Nova.

\section{O cristianismo, a Igreja e a sociedade na América Latina}

O cristianismo é um dos alicerces da civilização ocidental. A realidade social tal como foi configurada no curso do tempo está perpassada pela marca cristã. E essa mesma realidade forjou em muitos aspectos a própria expressão da fé.

E foi a fé cristã mediada pela Igreja Católica que aportou nas terras do Novo Continente no raiar do século XVI. "Os portugueses que descobriram as terras brasileiras e que nela se estabeleceram, colonizando-a gradualmente, trouxeram também a sua fé cristã e transferiram para a colônia boa parte da organização eclesiástica que já tinham no reino, bem como aplicaram com grande desenvoltura o Regime de Padroado régio que devia ser introduzido nas terras ultramarinas de Portugal." 2

Aquilo que se diz sobre a presença da Igreja na colonização portuguesa no Brasil, em certa medida, se aplica também a colonização espanhola.

Esse modelo eclesiástico é aquele típico da cristandade que vigorava no cristianismo ocidental. A cristandade surge do distanciamento histórico do evento Jesus Cristo, ampliando a própria noção de cristianismo, entendido em sentido estritamente religioso, para uma compreensão mais abrangente tendendo para o nível sociológico. O termo cristandade é antigo e acompanha praticamente toda a história da Igreja desde Constantino.

${ }^{2}$ A. KUHNEN, As origens da Igreja no Brasil, Bauru, Edusc, 2005, p. 25. 
Foi esse modelo eclesial europeu de cristandade que se firmou nas terras latino-americanas. Um modelo evangelizador mais eficiente em manter dentro dos limites da Igreja os imigrantes das levas de colonização e seus descendentes, ou seja, pessoas que já possuíam uma cultura cristã. Essa Igreja de cristandade não foi suficientemente profética e nem sensível para se opor a brutal dominação, submissão e violência perpetrada aos povos indígenas e africanos trazidos como escravos.

E foi justamente esse modelo eclesial que se deparou com um fenômeno novo que surgiu na Europa no início do século XVII, afetando todo o Ocidente. Trata-se daquilo que costumamos referir como modernidade.

\subsection{Igreja e modernidade}

A crise pela qual passou o cristianismo no período da modernidade tem um bom tanto de sua especificidade na forma institucional tal como ele foi apresentado. Por institucional entende-se a Igreja Católica. E foi justamente na Europa que se deu mais marcadamente a transição do período medieval para a época moderna. Diante da nova configuração social que surgia, com o fortalecimento de uma cosmovisão bem mais secular impulsionada pela nova ciência e a nova racionalidade a Igreja viu desabar sua compreensão de mundo e o sentido de sua presença na sociedade.

As novas classes emergentes, burguesia e proletariado, viam pouca utilidade na religião. Por seu turno, "a religião continuou forte nas classes sociais pré-modernas: aristocracia, artesãos, os pequenos comerciantes, os camponeses e em geral entre os conservadores ligados à sociedade tradicional." 3

Esse vento de modernidade que soprou forte na Europa perdeu um bom tanto de sua força ao cruzar o oceano. O advento da modernidade foi bem mais lento e bem menos drástico para a Igreja na América Latina.

Certamente com o fim da monarquia, fruto do espírito modernista, a Igreja, enquanto instituição, sobretudo no Brasil, perdeu um tanto do seu status diante do poder instituído. Por outro lado ganhou a liberdade e foi a partir desse momento histórico, com mais autonomia diante do poder político, que vemos surgir iniciativas de uma análise mais profunda da realidade social.

${ }^{3}$ G. BAUM, A modernidade: perspectiva sociológica, Concilium, fasc. 244, Petrópolis, Vozes, 1992, p. 10. 
Progressivamente cresce ao interno da Igreja a sensibilidade diante de realidades que destoam. Como entender que um continente marcadamente cristão seja, ao mesmo tempo, tão injusto e desigual na distribuição das rendas e na qualidade de vida?

É nesse período que a Igreja latino-americana ensaia passos mais determinados em voltar sua atenção para a problemática social. São feitas as grandes revisões, críticas de modelos colonizadores, desde a antiga colonização até os novos modelos de espoliação que continuam a existir na América Latina. Essa revisão ampla mobilizou boa parte da Igreja no continente desde a base, passando pelos filósofos, teólogos e intelectuais cristãos e chegando até membros da sua hierarquia.

Foi essa capacidade de olhar para a realidade social dos povos latinos que deu um tanto de vigor a Igreja latino-americana mesmo nos tempos críticos da modernidade.

Mas a realidade do tempo atual se configura de outra forma. Parece que estamos vivendo um momento acentuado de mudança, caminhando para além da modernidade.

\subsection{Igreja e pós-modernidade}

A realidade passa por um profundo processo de transformação. É o momento de transição daquilo que se convencionou chamar de modernidade para a pós-modernidade. Esse processo gera crises. "A crise atual não é apenas uma crise de indivíduos, governos ou instituições sociais; é uma transição de dimensões planetárias. Como indivíduos, como sociedade, como civilização e como ecossistema planetário, estamos chegando a um momento decisivo."

O Documento de Aparecida também se mostra atento a essa realidade de mudança de época. "Como se costuma dizer, a história se acelerou e as próprias mudanças se tornaram vertiginosas." (DA 34). "Essa nova escala do fenômeno humano traz conseqüências em todos os campos da atividade da vida social, impactando a cultura, a economia, a política, as ciências, a educação, o esporte, as artes, e também, naturalmente, a religião". (DA 35).

E no número 39 há uma constatação decisiva, uma espécie de divisor de águas para a ação da Igreja no tempo presente. "Esse fenômeno talvez explique um dos fatos mais desconcertantes e originais que vive-

\footnotetext{
${ }^{4}$ F. CAPRA, O ponto de mutação, São Paulo, Cultrix, 2006, p. 30.
} 
mos no presente. Nossas tradições culturais já não se transmitem de uma geração à outra com a mesma fluidez que no passado."

O que o documento não diz com todas as letras é que essa crise generalizada que atinge a realidade atual tem feito com que a cristandade caminhe para o seu ocaso.

Nesse tempo de pós-modernidade onde imperam o relativismo e o individualismo, a mensagem cristã ainda tem sentido? A busca de resposta dessa questão nos leva a um lugar comum e fundamental que é o próprio ser humano.

O ser humano pós-moderno é aquele que traz consigo todas as conquistas da modernidade. "Autonomia da cultura, a desvinculação do religioso e do político, a legitimidade do estado moderno como Estado de direito, a autonomia das sociedades civis sob orientação da razão democrática." ${ }^{5}$ Porém, todas essas conquistas da modernidade agora se refletem de maneira ainda mais pontual na configuração do indivíduo. A noção de cultura se torna bastante fraca diante de um indivíduo que vive num contexto globalizado, os elementos culturais perdem força a cada geração. Se antes assistimos a separação das esferas religiosas e políticas, hoje assistimos um distanciamento das tradições políticas convencionais. O ser humano hodierno é bem menos politizado no sentido tradicional do termo. Gradativamente perde força nas sociedades a capacidade de mobilização para grandes causas. O patriotismo está em declínio. Da mesma forma há um rompimento com a noção religiosa tradicional. É bem verdade que na pós-modernidade percebemos uma volta ao Sagrado. Deus voltou com relativa força, mas agora concebido de forma bem menos formal e doutrinal. As religiões tradicionais oscilam dentro de um campo de relativismo inerente na prática religiosa de seus membros em experimentar aquilo que lhes é mais agradável. Paradoxalmente o fenômeno religioso cresce e as religiões tradicionais diminuem. "O nosso tempo só logrou evacuar a escatologia revolucionária levando a cabo uma revolução permanente do cotidiano e do próprio indivíduo: privatização alargada, erosão das identidades sociais, desafeição ideológica e política, desestabilização acelerada das personalidades." ${ }^{\prime 6}$

É com essa individualidade marcada pela subjetividade que o cristianismo tem que dialogar. E o caminho mais promissor é sem dúvida res-

${ }^{5}$ C. GEFFRÉ; J. P. JOSSUA, Interpretação teológica da modernidade, Concilium, fasc. 244 , Petrópolis, Vozes, 1992, p. 5

${ }^{6}$ G. LIPOVETSKY, Era do vazio. Lisboa, Antropos, p. 7. 
gatar o essencial cristão vinculado as verdadeiras e profundas questões humanas.

\section{A mediação humana}

A Boa Nova é uma proposta e não mais que isso. Assim foi o princípio da pregação de Jesus e dos primeiros discípulos. Já passou o tempo em que o Evangelho se impunha por uma espécie de autoridade, seja ela representada na figura da tradição familiar, ou na pessoa do pregador eclesiástico.

Assim, somente uma autêntica preocupação com a realidade humana é que tornará significativa a Boa Nova para o contexto de pósmodernidade, caso contrário, os que pregam farão a experiência da indiferença sofrida por Paulo quando esteve no Areópago em Atenas: "te ouviremos mais tarde". (At 17, 32).

Uma leitura atenta das conclusões da Conferência da Aparecida nos permite afirmar a sensibilidade dos bispos no que se refere à realidade humana no nosso Continente. Sensibilidade despertada, sobretudo, em relação àqueles que estão à margem do lento processo de desenvolvimento vivido por nossos povos.

Refletindo a partir de Jesus Cristo, no capítulo VII do Documento de Aparecida, aparece com clarividência a real necessidade de tornar a vida nova trazida por Jesus Cristo uma realidade concreta para todas as pessoas.

No n. 353, por meio de diversas passagens bíblicas nos é mostrado como Jesus viveu se doando ao próximo. Jesus veio trazer o Reino de Deus, e nesse Reino todos são convidados à vida. No n. 359 , quando fala do sentido de redenção, o texto reafirma que esse sentido precisa atingir também o nível das relações inter-pessoais.

Em diversos números do DA aparece à preocupação com a problemática humana de forma bem definida. ${ }^{7}$ A Igreja representada nas conclusões da Conferência afirma sua convicção de que "Jesus Cristo é a resposta total, superabundante e satisfatória às perguntas humanas sobre a verdade, o sentido da vida e da realidade, a felicidade a justiça e a beleza." (DA 380).

O DA é bastante sensível em perceber a realidade difícil que atinge grande número de pessoas no Continente. Identifica com propriedade os

\footnotetext{
${ }^{7}$ Números 391-398 sobre a opção pelos pobres; 407- 430 sobre os moradores de rua, migrantes, enfermos, dependentes de drogas, detidos em prisão.
} 
problemas concretos dos povos, a maioria deles como conseqüência de estruturas sociais, políticas e econômicas injustas. Mas quando se trata de abordar questões de natureza existencial do ser humano na pósmodernidade, o documento apresenta certos limites.

Lipovestsky fala do processo de personalização com um dado realmente pós-moderno. "O ideal moderno de subordinação do individual às regras racionais coletivas foi pulverizado; o processo de pulverização promoveu e encarnou maciçamente um valor fundamental, o da realização pessoal, do respeito pela singularidade subjetiva." ${ }^{8}$ Esse processo de subjetivação não acontece da forma pacífica. Por isso, mais que em outros tempos percebemos o grande número de pessoas marcadas por uma subjetividade relativista, enfrentando constantemente dramas de natureza existencial. Pessoas com dificuldades de orientação e perseverança nas opções vocacionais, frustradas em suas expectativas e projetos pessoais. Noutras palavras, pessoas marcadas pela desesperança e que não encontram o sentido da vida.

Mas o cristianismo praticado nas Igrejas não sabe trabalhar com profundidade o indivíduo, menos ainda sua subjetividade. Desde cedo na tradição cristã o comunitário e coletivo se sobrepuseram ao individual. É bem verdade que essa prática, tal como nos testemunha os evangelhos, não encontra respaldo no agir de Jesus.

É preciso, no atual contexto histórico, desenvolver desde o nível da reflexão teológica, passando pela prática pastoral, formas de enfrentar essa realidade. É necessário entender o humano adentrando na sua condição individual. Esse é um desafio candente, cujas perspectivas ainda não foram suficientemente elaboradas.

Mas, como veremos a seguir, o DA firma um compromisso que ser for realmente assumido com todas as suas conseqüências, dará à Igreja latinoamericana, novo vigor, uma nova fisionomia possível de atingir positivamente o ser humano, tornando a proposta cristã hoje muito mais próxima do seu sentido original em Jesus Cristo.

\subsection{Converter cada cristão em discípulo missionário}

É no n. 362 que aparece um projeto ousado: converter cada "cristão em discípulo missionário". Isso será feito a partir do compromisso assumido de realizar uma grande missão em todo o Continente. Uma missão capaz de

\footnotetext{
${ }^{8}$ G. LIPOVETSKY, op. cit., p. 9.
} 
criar forte comoção e tirar as comunidades de seu comodismo, estancamento e indiferenças.

O cristianismo no Continente está ainda muito marcado por uma experiência religiosa, bem mais do que por uma experiência de fé. A experiência religiosa é aquela adquirida por vínculo de tradição familiar-comunitária, que situa a pessoa num espaço com linguagem comum para referir Deus, com liturgias e ritos partilhados. A experiência de fé é fruto daquele encontro pessoal e significativo com Deus que dá sentido fundamental para a vida e torna consistente a própria experiência religiosa.

Converter cada cristão em discípulo missionário é fazer com que a experiência religiosa se torne uma autêntica experiência de fé a partir de Jesus Cristo, tal como foi a experiência dos primeiros discípulos e da comunidade primitiva.

A questão que surge é se o atual modelo eclesial-pastoral realmente permite que esse processo seja realizado.

Quando lançamos os olhos para a vida e a missão de Jesus fica relativamente fácil compreender o fascínio que ele exercia diante das pessoas. Comportou-se como um homem livre, autêntico e perfeitamente à vontade para criticar a institucionalização presente na sua religião. Uma religião já estéril, burocratizada e insignificante para a realidade concreta das pessoas. Uma religião que havia perdido um bom tanto de sua transcendência por estar estacionada dentro de esquemas rigoristas e moralistas. Uma religião que tinha dificuldades de dizer algo ao ser humano.

Foi esse Jesus, fiel a intuição de fé mais profunda de sua cultura e, ao mesmo tempo, descentrado da caracterização religiosa de seu tempo, que fez discípulos, cativou pessoas e anunciou a Boa Nova de uma forma tão vívida que ele mesmo se tornou a própria Boa Nova. E foi a partir dela que surgiram as primeiras comunidades cristãs. Como uma proposta, nunca imposta, a Boa Nova de Jesus estava situada na realidade humana, para o humano, falando do humano, no concreto humano. O cristianismo lido em Jesus é extremamente humanizador.

Então quando o DA assume a grande missão de converter cada cristão em discípulo missionário, essa intenção só pode ser verdadeira se partir de Jesus Cristo, tal como nos é apresentado no Evangelho e que foi sucintamente descrito no n. 353.

Para tal intento será preciso muito mais do que aquela conversão pastoral descrita no DA, onde se faz um solene convite para que todas as comunidades entrem decididamente em processo de conversão constante de renovação missionária, abandonando as ultrapassadas estruturas que não favorecem a transmissão da fé. Noutras palavras, um apelo para a- 
bandonar o sacramentalismo que ainda impera nas comunidades. ${ }^{9}$ Mas essa conversão será conseqüência de um processo primeiro e fundamental que exigirá uma mudança radical de mentalidade ao interno da própria Igreja que deverá repensar com mais profundidade sua própria razão de ser.

Essa mudança radical passa pelo processo de descentramento da Igreja enquanto instituição. Na verdade não há novidade nisso, pelo menos não no plano teórico, mas certamente uma exigência nova e abrangente no nível prático.

A Igreja surge naturalmente na pregação da Boa Nova. O fortalecimento e a expansão do cristianismo e o distanciamento histórico de Jesus Cristo faz surgir à necessidade cada vez maior de institucionalização. $\mathrm{O}$ problema histórico é que a instituição por diversos momentos, uns mais outros menos, nem sempre soube encontrar seu verdadeiro papel no mundo ocidental.

Certamente tentar definir Igreja é uma tarefa perigosa e passível de equívocos e injustiças. Evidentemente a Igreja é uma instituição com status social definido. A história prova isso e prova muito bem. "É preciso distinguir, primeiro, o que é experiência original, impulso profético que chega a Jesus de Nazaré, e o que é institucionalização, inércia histórica, hábitos e idéias herdadas. Em segundo lugar, tampouco pode confundir-se o que é corpo eclesial, conjunto do povo crente, e o que é hierarquia dentro da Igreja." 10

Para enfrentar a realidade atual, onde tudo o que figura instituição histórica e autoridade é visto com certo receio, a Igreja precisa procurar seu lugar autêntico para ser significativa.

E para cumprir aquele projeto referido no n. 362 o melhor caminho é do descentramento de si mesma. Por descentramento entendemos o enfraquecimento do poder institucional para tornar a própria instituição, que é necessária, mais leve, mais livre para dedicar-se com verdadeiro ardor a causa do Reino.

Esse descentramento eclesial do qual estamos falando nada tem de anti-eclesial. Ao contrário, quer ressignificar a própria expressão eclesial. $O$ descentramento supõe sim um enfraquecimento da força e do poder da instituição hierárquica para reforçar o sentido de comunhão e participação. É até possível formular um paradoxo: Será cada vez mais forte a Igreja fraca. Certamente, essa é nossa percepção. A Igreja entendida como povo de Deus se fortalecerá muito mais se houver um enfraquecimen-

\footnotetext{
${ }^{9}$ Conversão pastoral e renovação missionária das comunidades estão nos números 365-372.

${ }^{10}$ A. T. QUEIRUGA, Creio em Deus Pai, São Paulo, Paulus, 2005, p. 16.
} 
to da Igreja instituição. Esse é um bom caminho para fazer surgir na pregação da Igreja aquele que é a sua própria razão de ser, que é o próprio Cristo. Só essa Igreja despojada de si, desvinculada do poder instituído e mais pobre é que poderá cumprir a contento a missão de converter cada cristão em discípulo missionário. Só os verdadeiros discípulos é que podem tornar a presença cristã promotora do bem humano. Serve para cada pessoa e também para a Igreja o apelo do Papa Bento XVI na homilia de inauguração do seu pontificado: "Não tenham medo de Cristo! Ele não tira nada e dá tudo!" (DA $352)$.

\section{Conclusão}

É quase que banal dizer que a relação entre Igreja e sociedade se deu de forma conflituosa na modernidade. O curioso é que o cristianismo exerceu um papel importante na gestação da própria modernidade, que concebe o sujeito livre e autônomo. Esses princípios tão caros para a racionalidade moderna são, num sentido mais amplo, fundamentados no que há de mais original no cristianismo. Então, não obstante a divergência verificada no nível institucional, a essência cristã não figura como inimiga do humano. De certa forma, é possível afirmar que a modernidade fez, com muitos limites, aquilo que a Igreja não conseguiu fazer a contento, ajudar o ser humano construir sua autonomia e sua liberdade. Nas metáforas de Jesus, "o sábado foi feito para o ser humano e não o ser humano para o sábado".

Por mais que essa verdade tenha ficado velada na história, o cristianismo é uma religião profundamente antropológica. O Deus revelado na vida de Jesus é a afirmação plena do humano. ${ }^{11}$ Essa verdade precisa transparecer cada vez mais tanto na reflexão teórica como na prática cristã dentro das comunidades eclesiais.

A grande missão da Igreja hoje é fazer com que o cristianismo seja compreendido nessa dimensão positiva e otimista. E isso só é possível, desde que feito a partir do anúncio de Jesus Cristo. Apresentar Jesus Cristo, o DA insiste nisso. Porque Jesus Cristo sempre tem algo de profundo e significativo para realidade humana. Independente do contexto, do tempo e do espaço o anúncio da Boa Nova de Jesus não será supérfluo, vazio ou ultrapassado.

Esse é a missão dos discípulos missionários. Discípulos de Cristo na Igreja, forjando uma Igreja discípula. E missionários no mundo e para o mundo para promover a vida plena vivida por Jesus. "Com alegria da fé,

${ }^{11}$ Tese que fundamenta o livro Creio em Deus Pai, de A. T. Queiruga. 
somos missionários para proclamar o Evangelho de Jesus Cristo e, Nele, a Boa Nova da dignidade humana". (DA 103).

\section{Bibliografia}

BAUM, Gregory, A modernidade: perspectiva sociológica, Concilium fasc. 244, Petrópolis, Vozes, pp. 788-796, 1992.

CAPRA, Fritjof, O ponto de mutação, São Paulo, Cultrix, 2006.

Compêndio do Vaticano II, Gaudium et Spes, Petrópolis, Vozes, 1991.

Documento de Aparecida, Texto Conclusivo da V Conferência Geral do Episcopado Latino-Americano e do Caribe, São Paulo. Paulus. 2007.

GEFFRÉ, Claude; JOSSUA, JEAN-PIERRE, Interpretação teológica da modernidade, Concilium fasc. 244, Petrópolis, Vozes, pp. 783-787, 1992.

KUHNEN, Alceu, As origens da Igreja no Brasil, Bauru, Edusc, 2005.

LIPOVETSKY, Gilles, A era do vazio, Lisboa, Antropos, 1983.

POULAT, Emile, Catolicismo e modernidade, Concilium fasc. 244, Petrópolis, Vozes, pp. 797-804, 1992.

QUEIRUGA, Andrés Torres, Creio em Deus Pai, São Paulo, Paulus, 2a ed., 2005.

RAHNER. Karl, Curso fundamental da fé, São Paulo, Paulus, 3ª ed., 2004.

Marcelo Batalioto

Mestrando em Teologia pela PUC-Rio 